\title{
ENTRE A LEGITIMAÇÁO E A CRÍTICA: As disputas acerca da Base Nacional Comum Curricular*
}

\section{Miqueli Michetti}

\author{
Departamento de Ciências Sociais, Universidade Federal da Paraíba (UFPB), João Pessoa - PB, Brasil. E-mail: miquelimichetti@gmail.com \\ https://orcid.org/0000-0003-2236-5126
}

DOI: $10.1590 / 3510221 / 2020$

\section{Apresentação}

Recentemente, a ideia de que uma base curricular nacional seria necessária para a melhoria da educação brasileira foi objeto de um acirrado debate. Não é de hoje, porém, que a educação é objeto de disputas no país. As principais concepções pedagógicas e práticas educacionais se constituíram e se consolidaram entre nós a partir de disputas entre grupos, valores e interesses distintos (Saviani, 2007; Cury, 2008). Atualmente, um dos agentes que tomam parte nessas disputas são organizaçóes sem fins lucrativos ligadas ao universo corporativo. Elas atuam de diversas maneiras, como em parce-

* A autora agradece a Fernando Burgos e aos/às pareceristas da RBCS pelas sugestóes a versóes anteriores do presente artigo.

Artigo recebido em: $27 / 01 / 2018$

Aprovado em: 22/08/2019 rias com secretarias municipais e estaduais de educação, na formação de "líderes", em premiações de "boas práticas", no financiamento de pesquisas na área de educação e na formação de "coalizões" para a consecução de políticas educacionais de amplo escopo, como a criação da chamada "Base Nacional Comum Curricular" (BNCC), tema central do presente artigo.

Vários trabalhos têm se dedicado a analisar a atuação de tais organizaçóes, tanto de forma mais geral (Freitas, 2012; Carvalho, 2017; Santos e Silva, 2017), quanto investigando instituiçôes e programas específicos (Adrião e Peroni, 2011; Peroni e Caetano, 2014; Urbini, 2015; Yada, 2016). Outras pesquisas se debruçam precisamente sobre a base curricular nacional (Alves, 2014; Cóssio, 2014; Batista et al., 2015; Limaverde, 2015; Peroni e Caetano 2015; Sousa, 2015; Macedo, 2014, 2015, 2016a; Barreiros, 2017; Avelar e Ball, 2019). Contudo, tais trabalhos são feitos 
majoritariamente a partir da área da Educação e do chamado "Campo de Públicas", e considera-se aqui que uma perspectiva mais marcadamente sociológica possa trazer contribuições à análise do processo de criação da BNCC. Ao mesmo tempo, a partir desse objeto empírico relevante por si só, é possível desenvolver ainda debates teóricos importantes na área da sociologia.

Desse modo, o artigo se debruça sobre o espaço social no qual a BNCC foi definida, bem como sobre as estratégias de legitimação, consensualização e concertaçáo discursiva estabelecidas pelos agentes que buscavam instituí-la, com foco na atuação de fundações e institutos familiares e empresariais. A centralidade de tais organizaçóes será um dos alvos das diversas críticas advindas de outros agentes implicados na disputa, as quais também são analisadas no texto.

Em termos metodológicos, entre 2015 e 2017, foram realizadas observações em eventos organizados no Brasil e nos EUA por fundações privadas brasileiras dedicadas à educação e em audiências públicas sobre a BNCC. Também realizamos entrevistas e análise documental de materiais diversos produzidos pelos agentes em questão. Por meio dessa base empírica, analisamos a atuação prático-discursiva dos agentes em disputa. Buscamos as recorrências discursivas, no sentido foucaultiano (Foucault, 2007) e, para efeito de demonstração no presente artigo, operamos a partir de exemplos heurísticos selecionados após saturação de enunciados e práticas recorrentes. Essa frente discursiva foi trabalhada levando em conta o espaço social em que ela emergia (Bourdieu, 1989, 1996, 2004). A partir de uma apropriação livre das concepçóes de Bourdieu acerca da composição relacional de espaços sociais em que agentes com diferentes posiçóes e capitais desiguais estabelecem disputas e de um diálogo implícito com a Teoria do Discurso, buscamos, na trilha de Reed (2013, p.211), integrar as dimensóes relacional e discursiva das disputas.

Além dessas orientaçôes teórico-metodológicas, o fato de estarmos diante de uma polêmica pública trouxe uma interlocuçáo com a chamada Sociologia Pragmática e com a Sociologia da Controvérsia. Tal como essas vertentes, concebemos as controvérsias públicas como formas de adentrar a ordem social e a sua problemática reprodução (Barthe et al., 2013, p.177). Contudo, buscamos integrar algumas contribuiçóes dessa perspectiva, que se coloca criticamente em relação à sociologia de Bourdieu, sem refutar por completo o legado bourdieusiano, ainda que, por si só, este não alcance explicar nosso objeto. Diante disso, procuramos, como Bernard Lahire (2002, p.11), "pensar, ao mesmo tempo, com e contra [...] Pierre Bourdieu”. É com essa mesma postura que trabalhamos com a Sociologia da Crítica e da Justificação, de Luc Boltanski e Laurent Thèvenot, para refletir sobre o lugar da crítica no processo de criação da BNCC.

Quanto ao percurso do artigo, após essa apresentação, introduzimos o espaço social da disputa recente em torno da BNCC e expomos o que chamamos de "estratégias de consensualização" estabelecidas pelos agentes favoráveis a ela, com ênfase no âmbito discursivo de tais estratégias. Passamos, na sequência, às críticas proferidas por agentes contrários seja à premissa de que uma base curricular era necessária, seja ao conteúdo, aos artífices e ao processo de constituição do documento. Analisamos, então, as complexas relaçóes entre crítica e legitimação no processo em tela e, a partir dos resultados oriundos da investigação empírica, concluímos com apontamentos sobre a conveniência de uma abordagem multidimensional das disputas sociais.

\section{O espaço social do debate sobre a Base Nacional Comum Curricular}

As disputas acerca da criação da base curricular nacional se dão no seio de um espaço social em que vários agentes - com acúmulos desiguais de variados capitais e com ethos, interesses e estratégias diversos - buscam fazer valer sua posição como legítima e encaminhar seus desígnios. Embora o emprego da perspectiva bourdieusiana seja evidente, a noção de espaço social será privilegiada aqui por não acarretar o fechamento e a autonomia implicados no conceito de campo. A disputa que aqui analisamos não se restringiu ao que seria o "campo" da educação no Brasil, sendo conformada também por alguns agentes e tipos de capital que, em definição estrita, seriam externos a ele. Por isso, em vez de 
(re)delinear fronteiras que teriam de ser pensadas como demasiadamente porosas ou alargadas para funcionar analiticamente, ou de insistir na ideia de uma autonomia muitíssimo relativa do campo, preferimos trabalhar com a concepção mais ampla de espaço social, a qual permite pensar relacionalmente os agentes em disputa sem implicar nos difíceis equilíbrios analíticos que seriam necessários para enquadrar nosso objeto empírico como um campo.

Cabe ressaltar, ainda, que concebemos a noção como não necessariamente excludente à perspectiva que enxerga a criação da BNCC como resultado da atuação "em rede" de determinados atores (Macedo, 2014; Avelar e Ball, 2019). Ainda que as duas abordagens sejam teoricamente divergentes (Sapiro, 2006, p.46-9) e que não seja este o foco do presente artigo, diferentes tentativas de conciliá-las têm sido consequentes, especialmente em termos metodológicos. Enquanto alguns autores buscam congregar as vertentes teoricamente (Bottero e Nick Crossley, 2011; Marco Serino et al., 2017), estudos como os de Gisèle Sapiro (2006) e Elisa Klüger (2017) apostam coerentemente no potencial metodológico de se trabalhar a "teoria dos campos" ou a perspectiva do espaço social por meio da análise de redes.

Além disso, a abordagem calcada na ideia de espaço social não é mutuamente exclusiva à vertente que analisa o componente discursivo da disputa que nos concerne (Macedo, 2014, 2015, 2016a, 2016b; Barreiros, 2017). Pelo contrário, a dimensão discursiva é um dos elementos centrais do presente artigo, mas a sublinhamos como integrante de um espaço social constituído relacionalmente e em cuja conformação o componente simbólico é fundamental. Ela é constituída em, constituida por e constituinte de um espaço social, de modo que é mais consequente operar simultaneamente com as dimensôes relacional e discursiva para apreender como, por quem, contra quem, em qual contexto e com quais implicaçôes algo é enunciado.

Convém precisar ainda que, para Bourdieu, os agentes teriam um domínio antes prático que reflexivo da estrutura social (1989, p.141). Ou melhor, para o autor, "O habitus é ao mesmo tempo um sistema de esquemas de produção de práticas e um sistema de esquemas de percepção e apreciação das práticas". Por exprimir "a posição social em que foi construído", o habitus implicaria "não apenas um sense of one's place, mas também um sense of other's place” (Bourdieu, 2004, p.158). Já a chamada Sociologia Pragmática afirma que os atores, ao atuar, possuem diferentes graus de reflexividade e que as "situações públicas" - como a que temos em vista seriam caracterizadas por "formas de reflexividade máxima" (Barthe et al., 2013, p.188). Para os propósitos deste artigo, o que importa é que, seja via percepçóes classificatórias das posiçóes no espaço social - do sense of places -, seja via reflexividade dos atores, os agentes em disputa atuam, na situação que analisamos, conforme uma apreciação que eles próprios têm do espaço social em que agem, isto é, das posiçóes e dos diferentes capitais em disputa. Ainda que os termos enunciados não sejam esses, age-se a partir de alguma avaliação sobre "quem é quem".

Dito isso, o espaço social onde se dá a disputa sobre a BNCC é formado por agentes do poder executivo dos três níveis de governo, que conformam o "pacto federativo" da educação no país, e do legislativo federal, no qual a Comissão de Educação $^{1}$ tem centralidade. O Ministério da Educação (MEC) representou o executivo federal, enquanto o Conselho Nacional de Secretários de Educação (Consed) foi o representante do âmbito estadual, e a esfera municipal foi representada pela União Nacional dos Dirigentes Municipais de Educação (Undime). Estiveram presentes também instâncias de "interlocução entre sociedade civil e o Estado", como o Conselho Nacional de Educação (CNE) e o Fórum Nacional de Educação. Atuaram, ainda, associaçóes civis sem fins lucrativos, em especial o Movimento pela Base (MpB), mas também o Todos pela Educação (TpE) e, individualmente, institutos e fundaçóes familiares e empresariais.

Em posições não-dominantes, estiveram a Campanha Nacional pelo Direito à Educação $(\mathrm{CNDE})^{2}$, as associaçóes de pesquisadores da área de educação, como a Associação Nacional de Pós-Graduação e Pesquisa em Educação (Anped), a Associação Brasileira de Currículo (ABdC), bem como centros de estudo e pesquisa de faculdades de educação - especialmente de universidades públicas -, associaçôes de ensino diversas e entidades, como a Associação Nacional de Política e Administração em Educação (Anpae), a Associaçáo Nacional pela 
Formação dos Profissionais da Educação (Anfope) e o Fórum Nacional de Diretores de Faculdades/ Centros/Departamentos de Educação ou Equivalentes das Universidades Públicas Brasileiras (Forumdir). Organizaçóes sindicais de trabalhadores da educação, particularmente de professores - como o Sindicato Nacional dos Docentes das Instituiçóes de Ensino Superior (Andes-SN) e a Confederação Nacional dos Trabalhadores da Educaçáo (CNTE) -, também se colocaram nos debates.

Todos esses agentes estabelecem relações a partir das posiçôes que ocupam no espaço social das disputas pelos destinos da educaçáo no país. Como apontam Simielli e Alves ao analisar a querela entre TpE e CNDE,

[...] há uma pluralidade de atores, grupos e instituiçóes em conflito, alguns deles detentores de uma posição vantajosa em relação aos demais, decorrente da desigualdade na distribuiçấo de recursos materiais, organizacionais e simbólicos (2011, p.15).

As vinculações de entes públicos e privados com o Consed e a Undime constituem um bom exemplo das articulaçóes entre os agentes mais bem posicionados na disputa. A aliança com essas duas organizaçōes foi privilegiada por agentes públicos e privados porque elas responderiam pela implementação da Base e poderiam ser consideradas, para efeitos de legitimação - não sem contestação -, como representantes públicos do universo escolar. $\mathrm{Na}$ qualidade de "parceiros", elas declaram órgãos e instâncias de governo, organismos multilaterais, associaçōes civis, fundações e associaçōes ("institutos") privadas e empresas ${ }^{3}$. Destacando apenas as fundaçóes empresariais e familiares, temos, como parceiros da Undime, a Fundação Victor Civita, a Fundação Abrinq, a Fundação Itaú Social, o Instituto Natura, a Fundaçáo Telefônica Vivo, o Instituto Alana, a Fundaçáo Lemann e a Fundação SM. E, como parceiros do Consed, estão a Fundação Roberto Marinho, a Fundaçáo Itaú Social, o Instituto Unibanco, a Fundação Victor Civita, o Instituto Natura, a Fundaçáo Santillana, a Fundação Lemann, a Fundação Telefônica Vivo, além das empresas Gerdau e Itaú BBA.
Embora não sejam as únicas, tais organizaçóes são bastante representativas de agentes que ocuparam posições centrais no espaço social dos debates sobre a BNCC, no qual os agentes em posição dominante - como o poder público, as fundaçóes privadas e as empresas - contam com maior montante de capital político, social e econômico. Contudo, por se tratar de um debate em torno da educação, uma área considerada pública, o capital econômico encontra dificuldade em ser tomado como legítimo, de forma que os agentes munidos desse capital buscarâo convertê-lo em capital simbólico (Michetti, 2017). Tal operação será criticada por posiçōes não dominantes no processo de elaboração da Base, as quais, embora não dominantes, por concernirem à educação pública, contam com capital social $\mathrm{e}$ com um alto montante de capital simbólico. Existem várias posiçôes entre essas duas extremidades, contudo, elas delineiam os eixos em torno dos quais a polêmica se desenrolou.

\section{Estratégias de legitimaçáa em torno da BNCC: consensualização e concertaçáo discursiva}

Tema pouco propício a consensos, a formaçáo educacional das geraçôes futuras constitui uma arena de disputas, como ficou claro quando da criaçáo das Leis de Diretrizes e Bases (Macedo, 2015; Costa, 2002; Adriāo e Oliveira, 2001) e dos Parâmetros Curriculares Nacionais (Horta, 1997). Diante disso, o núcleo de agentes que encaminhou a criação e aprovação da BNCC estabeleceu várias estratégias prático-discursivas com vistas à consensualização do debate e à legitimação do documento. Em algumas delas, a frente prática é predominante, ao passo que em outras o elemento discursivo é o mais marcante. Entretanto, com Bourdieu, concebemos que as práticas têm um componente simbólico e, com Fairclough (2001, p.91), que os discursos são "uma forma particular da prática social", de modo que discursos e práticas se imbricam nas estratégias demonstradas a seguir.

Criação de um grupo formal para avançar a BNCC: em 2013, foi formado o chamado "Movimento pela Base" $(\mathrm{MpB})$, que se apresenta como 
"um grupo de especialistas em Educação", [que] "se reuniu para discutir a adoção de uma Base Nacional Comum no Brasil”. Este grupo buscaria

[...] facilitar o processo de construção da Base, apoiando e disseminando pesquisas e insumos técnicos para qualificar o debate e mobilizando atores chave (gestores, acadêmicos, pesquisadores, professores, líderes da sociedade civil organizada $)^{4}$.

$\mathrm{O} \mathrm{MpB}$ faz referência a duas fontes de legitimidade: os "especialistas" e a "sociedade civil organizada”, recorrendo tanto à legitimação técnico-científica quanto à da vontade geral. Contudo, entre "especialistas" e "líderes da sociedade civil organizada”, encontramos nomes oriundos de importantes famílias e grupos empresariais nacionais, que integram a organização especialmente por meio de fundaçóes e "institutos" ligados ao universo corporativo. Entre os "apoios institucionais" ao $\mathrm{MpB}$, temos Undime e Consed, membros e ex-membros do CNE, o secretário de educação básica e a diretora de currículos e educação Integral do MEC, a presidente do Inep, secretários e ex-secretários estaduais de educação, alguns professores e pesquisadores, um "Consultor Legislativo da Câmara dos Deputados na área de Educação" e três deputados federais ${ }^{5}$. A propósito, a fundação oficial do $\mathrm{MpB}$ se deu no mesmo abril de 2013, quando a Lei $n^{\circ} 12.796$, inserindo a referência a uma "Base Nacional Comum" na LDB, foi aprovada na Câmara dos Deputados ${ }^{6}$.

Daí em diante, o $\mathrm{MpB}$ passa a atuar para a construção no Brasil de um "common core" semelhante ao existente em países como EUA, Reino Unido, Austrália e Chile ${ }^{7}$. Entretanto, uma empreitada pública dessa envergadura não poderia ser levada a cabo exclusivamente por atores privados, que serão, então, enunciados como coadjuvantes, ainda que tenham boa dose de protagonismo, e que logo tomarão por tarefa a composição com agentes públicos e privados em torno do objetivo enunciado como comum.

Multiposicionalidade dos agentes: no processo de criação da Base, pessoas e organizaçóes ocuparam diferentes cargos e espaços, integrando-os em torno de uma mesma pauta. Para evocarmos apenas dois exemplos, temos, como indivíduo, o caso de Eduardo Deschamps, que ocupou diversas "cadeiras" ao longo do processo de criação da BNCC; e, como organização, a Fundação Lemann também tem esse modus operandi tentacular, multiposicional e, em muitos momentos, sua atuação confunde-se com a do $\mathrm{MpB}$.

Ao continuar suas reflexões sobre as "funções sociais da multiplicidade de posiçóes" (Boltanski, 1973, p.23-5), Boltanski afirma que a multiposicionalidade dos atores no espaço social dificultaria a clareza sobre as diferentes posiçóes ocupadas, de modo que esta pode ser uma estratégia para contornar ou dissimular situaçóes em que instituiçóes enfrentam críticas (Boltanski, 2009, p.179). Avelar e Ball (2019, p.5) consideram as conexōes entre membros de diferentes organizaçóes como uma "rede" em transformação. Empregamos, porém, a ideia de multiposicionalidade para sublinhar que os agentes mais bem posicionados podem utilizar seu capital social, mas também econômico e político, para conformar um espaço social, delinear suas pertenças e exclusóes. Se a multiposicionalidade só é possível quando já existe alinhamento entre indivíduos e organizações, ela é também um dos veículos de consensualização.

Realização de eventos nacionais e internacionais: financiados por fundaçóes privadas, tais eventos congregaram atores-chave e foram realizados a partir de 2013, majoritariamente em universidades estadunidenses de prestígio. Enquanto os encontros do $\mathrm{MpB}$ ocorreram na Yale University, outros eventos promovidos pela Fundação Lemann foram realizados nas universidades dos EUA nas quais ela financia centros de pesquisa sobre Brasil. Tais centros, da Columbia University, Harvard University, University of Illinois e Stanford University, organizam anualmente o "Lemann Dialogue", evento que reúne acadêmicos, empresários e agentes do poder público, de organismos internacionais e da chamada sociedade civil para a discussão de questóes consideradas estratégicas para o Brasil, como a educação. Seminários específicos sobre a BNCC, financiados pela Fundação Lemann, também ocorreram em Campinas e em São Paulo ${ }^{8}$. Tal como colocam Avelar e Ball (2019, p.4), tais eventos são importantes para a criação de uma "comunidade de cren- 
ças, valores, culturais e formas de comportamento compartilhados".

Alianças e vinculaçóes estratégicas: além de serem, em termos bourdieusianos, momentos rituais em que se consolida a "conversão" dos atores a uma mesma "crença", os vínculos com universidades consagradas foram usados como uma espécie de "lastro técnico-científico" a partir do qual enunciou-se a expertise dos "especialistas em currículo internacionais" escalados para tomar parte na formação da BNCC. Além disso, temos a presença "do pessoal das fundaçôes" em Brasília, "no dia-a-dia" com parlamentares federais. No texto de Avelar e Ball (2019), essa situação é descrita como lobby, enquanto nas entrevistas realizadas para essa pesquisa, os atores usam o termo advocacy.

Construção do apoio da "grande mídia": a concentração de capital econômico, social e político dos agentes favoráveis à Base teve papel na concertação discursiva junto a veículos da chamada grande mídia ${ }^{9}$, como dá a entender, por exemplo, a fala de um ator principal do Centro Lemann de Stanford: "essa [base curricular] não era uma pauta, muito menos consenso. Isso virou consenso, porque a Fundação [Lemann] pode passar a mão no telefone e falar direto com os Frias" 10 (fazendo referência ao jornal Folha de São Paulo).

Enunciação de objetivo incontestável: todos os atores do núcleo formador da Base enunciaram reiteradamente e em uníssono que o objetivo central dela seria a "garantia de uma educação de qualidade" com mais "equidade", já que incidiria tanto sobre o ensino público, como o ensino privado, e cobriria a extensão do território nacional. Tal enunciação se manteve inalterada, ao passo que vários outros objetivos evocados ao longo dos debates oscilaram diante das críticas, ou eram matizados em função dos fóruns nos quais eram enunciados, como, por exemplo, o referente à necessidade de um aprendizado verificável, mensurável e classificável por testes nacionais e internacionais, bem como o da equiparação do sistema brasileiro aos modelos internacionais de matriz curricular.

Narrativa genealógica: um aspecto central na concertação discursiva em torno da Base foi a enunciação de um "marco legal" discursado como historicamente consolidado, putativamente cons- tituído pelo artigo 210 da Constituição de 1988, segundo o qual "Serão fixados conteúdos mínimos para o ensino fundamental, de maneira a assegurar formação básica comum e respeito aos valores culturais e artísticos, nacionais e regionais"; pela Lei no 12.796, de 2013, que insere o termo "Base Nacional Comum" no artigo 26 da LDB de 1996; bem como pela lei no 13.005 , que promulga o Plano Nacional de Educação em 2014.

Depois do envio da terceira versão da BNCC ao CNE, o MEC divulgou, inclusive, uma "linha do tempo" com uma genealogia da Base, que vai de 1988 a $2017^{11}$. No que se refere a esse aspecto, podemos retomar Bourdieu (2004, p.162), quando ele afirma que as "mais típicas" das "estratégias de construção da realidade social são as que visam reconstruir retrospectivamente um passado ajustado às necessidades do presente". E podemos também fazer referência à sociologia pragmática, quando ela destaca a importância de se atentar aos usos sociais e políticos do passado pelos próprios atores (Barthe, 2013, p.181).

Composição discursiva entre expertise e democracia: buscou-se amalgamar dois modelos de justificação, nos termos de Boltanski e Thévenot (1991): um atinente à deliberação democrática e outro à formulação de especialistas. Essa composição aparece no MEC, conforme segue:

A BNCC é fruto de amplo processo de debate e negociação com diferentes atores do campo educacional e com a sociedade brasileira. A primeira versão do documento foi disponibilizada para consulta pública entre outubro de 2015 e março de 2016. Nesse período, ela recebeu mais de 12 milhôes de contribuiçóes - individuais, de organizaçóes e de redes de educação de todo o País -, além de pareceres analíticos de especialistas, associações científicas e membros da comunidade acadêmica. As contribuiçóes foram sistematizadas por pesquisadores da Universidade de Brasília (UnB) e da Pontifícia Universidade Católica do Rio de Janeiro (PUC-RJ) e subsidiaram a elaboração da segunda versão. Publicada em maio de 2016, a segunda versão da BNCC passou por um processo de debate institucional em seminários realizados pelas Secretarias 
Estaduais de Educação em todas as Unidades da Federação, sob a coordenação do Conselho Nacional de Secretários de Educação (Consed) e da União Nacional dos Dirigentes Municipais de Educação (Undime). Os seminários estaduais aconteceram entre 23 de junho e 10 de agosto de 2016 e contaram com a participação de mais de 9 mil professores, gestores, especialistas e entidades de educação, encerrando o ciclo de consulta previsto para a segunda versão. Seus resultados foram sistematizados e organizados em relatório produzido por um grupo de trabalho composto por Consed e Undime, com base em análise realizada pela UnB. A segunda versão da BNCC foi examinada também por especialistas do Brasil e de outros países. Anexados ao relatório Consed/Undime, os pareceres analíticos desses especialistas foram encaminhados ao Comitê Gestor da Base Nacional Curricular Comum e Reforma do Ensino Médio, instituído pela Portaria MEC no 790/2016. Entre outras atribuições, o Comitê Gestor é responsável pelas definições e diretrizes que orientaram a revisão da segunda versão, bem como pela indicação dos especialistas que redigiram a versão final [...]. Também esta versão da BNCC, em distintos momentos de sua elaboração, foi analisada por leitores críticos (especialistas, associaçóes científicas e professores universitários), que produziram pareceres relativos às diferentes etapas da Educaçāo Básica, às áreas e aos componentes curriculares do Ensino Fundamental. ${ }^{12}$

\section{$\mathrm{O} \mathrm{MpB}$ a enuncia nesses termos:}

O Ministério da Educação (MEC) iniciou a redação do documento em 2015, em colaboração com membros das secretarias municipais e estaduais de educação, acadêmicos especialistas nas disciplinas e professores da Educação Básica. Em setembro de 2015, o MEC publicou a primeira versão da Base. O documento foi aberto para que qualquer cidadão pudesse fazer comentários, sugestóes ou críticas. A consulta pública foi encerrada em março de 2016, com mais de 12 milhôes de contribuiçóes por meio do site http://basenacionalcomum.mec.gov.br. A se- gunda versão da Base, redigida de acordo com essas contribuiçóes e com o debate público, foi apresentada pelo MEC em maio de 2016. O texto foi analisado entre junho e agosto em seminários realizados em todos os estados. Organizados pelo Conselho Nacional de Secretários de Educação (Consed) e pela União Nacional de Dirigentes Municipais de Educação (Undime), os seminários reuniram mais de 9 mil participantes, a maioria professores, que puderam fazer sugestóes de mudanças. Essas contribuiçóes foram sistematizadas em um relatório, entregue ao MEC em 14 de setembro de 2016. A terceira versão do texto da Base, redigida a partir das recomendações dos seminários, foi entregue ao Conselho Nacional de Educação (CNE) em 6 de abril de 2017. O CNE irá realizar audiências públicas entre junho e outubro de 2017 para emitir um parecer. O documento volta então ao MEC, para homologação. Começa a fase de implementação: a expectativa é de que a Base chegue nas salas de aula em até dois anos depois da homologação ${ }^{13}$.

O CNE - instância a emitir o parecer último da BNCC, e que, ao mesmo tempo, representa oficialmente a sociedade civil e congrega "especialistas" - sublinha o caráter participativo das audiências regionais, asseverando que as realizou "mediante a participação da sociedade no debate do documento", e que nelas "os mais diversos segmentos da sociedade terão oportunidade de oferecer suas contribuiçóes", embora elas não tivessem caráter deliberativo $^{14}$.

Fundação Lemann e MpB reforçam o enunciado da democracia, tal como no material divulgado, sintomaticamente em conjunto, por ambas organizaçóes após as audiências públicas: "A Base está sendo construída desde 2015 com participação ativa da sociedade"; "O caráter democrático é reforçado pelos integrantes da última audiência pública [...], que contou com pessoas contra e a favor da Base". No mesmo texto, lê-se a afirmaçáo lapidar de Eduardo Deschamps, já na presidência do CNE: "Essa Base não é do MEC. Não é do CNE. É do Brasil" 15 .

Findas as audiências, o MEC divulgou a terceira versão da BNCC em publicação apresentada 
como uma "parceria com Consed e Undime" e com o "apoio do Movimento pela Base". Logo na apresentação, estatui-se que o "foco principal” da BNCC são "a igualdade e a unidade nacional" (Brasil, 2017, p.11). Na sequência, enunciam-se explicitamente os pilares sobre os quais se buscou erigir sua legitimidade, calcada no "pacto interfederativo, nos termos da Lei no 13.005/ 2014, que promulgou o PNE"; bem como no fato de que "Sua formulação, sob coordenação do MEC, contou com a participação dos Estados, Distrito Federal e Municípios, depois de ampla consulta à comunidade educacional e à sociedade" (Brasil, 2017, p.14).

Ao noticiar a aprovação da BNCC pelo CNE, além de reiterar a "cronologia" da norma, o MEC insiste que:

A BNCC foi construída ao longo de mais de três anos, sob a coordenação do MEC e com a colaboração de milhares de educadores, especialistas e acadêmicos de todas as regióes do país ${ }^{16}$.

$\mathrm{Na}$ cerimônia de homologação da base pelo MEC, realizada em 20/12/2017, Mendonça Filho, que assumiu a posição de Ministro da Educação em maio de 2016, sob o governo de Michel Temer, afirmou que:

A base é plural, respeita as diferenças, respeita os direitos humanos, nenhuma prisão com relação à ideologia de gênero, muito pelo contrário. Mas ela é fruto de uma construção coletiva ${ }^{17}$.

$\mathrm{Na}$ mesma ocasião, o presidente da Undime confirmou:

Foi um longo processo de discussão e debates para chegarmos até aqui. Desde 2014 a Undime participou desse processo, que foi diferente dos processos de outros países. O processo brasileiro tem a cara do Brasil, do tamanho e da diversidade do Brasil. Foi longo e envolveu muita gente e diferentes estratégias. Por isso, esse momento é histórico. A sociedade precisou de 4 anos para construir a BNCC. Essa é uma conquista do povo brasileiro ${ }^{18}$
Esse material, selecionado de um corpus mais amplo, torna explícita a existência de uma recorrência discursiva em torno de dois enunciados principais: a) o caráter colaborativo e democrático da construção da Base; e b) o caráter técnico garantido pela contribuição de "especialistas" em sua formulação. Diante disso, é interessante retomarmos a distinção que Boltanski (2009, p.178) estabelece entre instituiçóes que, em seu esforço de justificação, reivindicam a "vontade geral", e aquelas que se apoiam na expertise, na autoridade da ciência. Mais do que uma simples diferença ou oposição entre elas, no processo que aqui analisamos, ambas as frentes foram evocadas como diferentes lastros para capitais simbólicos distintos em disputa pelos agentes interessados em legitimar a BNCC.

Em geral, alguns agentes ocupam uma posição mais ligada à vontade geral, e outros, à autoridade científica. Não obstante, institutos e fundaçóes vinculados ao mundo corporativo buscarão enunciar-se a partir das duas frentes, como "sociedade civil" e como agremiação de "especialistas". Eles evocam as duas espécies de capital simbólico em jogo no arranjo de legitimidade, porém, boa parte de sua posiçáo é assegurada por um capital que não se explicita nos debates, a não ser de forma crítica, a partir de fora do núcleo de formação da Base. Trata-se do capital econômico, ao mesmo tempo ubíquo e impronunciável no que tange à presença desses agentes no espaço social que temos em tela. Como o capital econômico não é visto como legítimo nesse debate, seus detentores buscam recorrer às duas fontes de legitimidade já apontadas.

Contudo, as várias estratégias de consensualização apresentadas se dão em meio a críticas e contestaçóes. Empregamos o termo consensualização justamente para indicar que não se trata de um consenso, mas de uma forma sistemática e coordenada de lidar com o dissenso e com as críticas, como veremos a seguir.

\section{As críticas oriundas das posiçốes avessas à consensualização}

Enquanto certos agentes buscavam encerrar as disputas por meio do que chamamos de consensua- 
lização, outros atores pediam a (re)abertura do debate ou o denunciavam como meramente formal. Buscamos "levar a sério" as críticas que os próprios atores estabeleceram, tal como sugere a Sociologia da Crítica, proposta por Boltanski em oposição ao que seria a "Sociologia Crítica" bourdieusiana. Tais perspectivas costumam ser vistas como irreconciliáveis na teoria sociológica, entretanto, levamos a sério as críticas dos atores, mas as apreendemos como sendo realizadas dentro de um espaço social no qual eles agem relacional e reflexivamente.

Com isso em mente, foi possível perceber dois conjuntos de estratégias críticas. Um deles teve lugar no interior do universo institucional em que se buscava avançar a Base, no qual agentes privados e instâncias públicas organizaram procedimentos formais de recepção de críticas. O outro se expressou a partir de fora de tal universo. Estas estratégias não se deram de forma completamente independente entre si, pois houve atravessamentos entre elas, sendo que vários atores, com diferentes acúmulos de capitais e graus de legitimidade, envolveram-se nos dois tipos de iniciativa ou transitaram entre elas. Além disso, cabe apontar que ambas se construíram relacionalmente e por oposição às posições que defendiam a BNCC.

Participação crítica nos espaços formais: críticas e oposiçóes foram explicitadas nas Audiências Públicas Regionais organizadas pelo CNE para discussão do documento curricular. Elas eram abertas a inscriçôes de "instituiçóes convidadas" e do "público geral”, no entanto, os participantes eram, em sua maioria, representantes de entidades convidadas e as inscrições de pessoas físicas ficavam muito aquém da demanda. Nessas ocasióes, enquanto a organização do evento asseverava que todos seriam ouvidos, os representantes das entidades se sucediam ao microfone e acusavam a Base de negligenciar aspectos importantes da educação, como, por exemplo, educação física, filosofia, questóes de gênero, diversidade... Além disso, criticavam marcadamente como insuficiente, para suas consideraçóes, o tempo de três minutos do qual dispunham, denunciando, assim, o processo de escuta como meramente formal. Tal crítica apareceu em todas as audiências, cujo caráter "não deliberativo" ou não estava claro para todos os participantes ou estes se recusavam a aceitar isso como fato.
Os procedimentos de participação preparados pela Comissão de Educação da Câmara dos Deputados - como o "Ciclo de Debate" ${ }^{19}$ e os "Seminários", em que "entidades e movimentos da sociedade ligados à educação, além de especialistas, professores e parlamentares" reuniram-se "para debater a Base Nacional Comum Curricular" ${ }^{20}$ constituíram outra instância institucional em que ecoaram críticas à BNCC.

Também nos eventos sobre educação pública promovidos por fundaçóes privadas nos EUA e no Brasil - em geral, com participação de representantes de entes públicos -, o descontentamento de parte do público e mesmo de alguns integrantes das mesas ficou patente. Ainda que fossem encontros reservados a convidados, críticas emergiram, por exemplo, na edição de 2015 do Lemann Dialogues, ocorrida na Columbia University, em Nova York, bem como no "Seminário Internacional do Centro Lemann para o Empreendedorismo e Inovação na Educação Brasileira em Stanford”, realizado em 2016 na FAAP, em São Paulo, com o tema "Como a Base Nacional Comum pode contribuir para uma educaçáo pública de qualidade?"21.

Estratégias criticas externas aos espaços formais: o polo da crítica também organizou diferentes tipos de eventos e produziu documentos de diversos teores contrários à Base. Assim como na esfera da legitimação, foi igualmente possível perceber, no espaço da crítica, a mobilização de aspectos mais ligados ao argumento político-democrático e outros mais atinentes às características do conteúdo do documento proposto. Típico-idealmente, organizaçôes sindicais e de representação política da educação pública, atuando ancoradas sobretudo no capital simbólico de teor político, responderiam pela primeira vertente. Por sua vez, a esfera acadêmica, baseada principalmente no capital simbólico de teor cultural-científico, se ocuparia da formulação da crítica especializada. Contudo, tais ancoragens também se imbricaram no processo de elaboração crítica à BNCC, não havendo, assim, uma cisão absoluta entre os dois tipos de atores. Ainda que tenha sido possível apreender suas especificidades, verificaram-se trânsitos tanto entre ancoramentos políticos e acadêmicos, quanto entre dinâmicas de críticas internas e externas. 
Isso posto, é interessante olharmos para alguns exemplos heurísticos de como tais posiçóes se colocaram a partir de fora dos espaços de deliberação sobre a Base. A Confederação Nacional dos Trabalhadores da Educação (CNTE), que reúne sindicatos da categoria, apresentou forte oposição à BNCC ao longo de todo o processo e organizou "eventos paralelos" às audiências regionais do CNE, os quais foram apresentados

[...] como forma de denúncia à tendência privatista da educação básica pública no Brasil e o empobrecimento do currículo das escolas. [...] a redação do documento foi feita sem a participação social e há a necessidade de ser discutida a partir da escola, como determina a Lei de Diretrizes e Bases da Educaçáo Nacional, e não de dentro do MEC [...]. O objetivo é que as reflexôes, coordenadas pelas entidades populares, fomentem novo parâmetro na discussão da Base, com enfoque voltado à defesa intransigente da educação pública, de boa qualidade e socialmente referenciada, além de permitir a participação efetiva da sociedade civil organizada [...]. Os resultados dos debates, previstos para ocorrerem, ainda, em São Paulo e Brasília, vão gerar documento alternativo ao proposto pelo $\mathrm{MEC}^{22}$.

O Sindicato Nacional dos Docentes das Instituiçóes de Ensino Superior (Andes-SN) também se posicionou contrariamente à $\mathrm{BNCC}$,

[...] por entender que a ela está vinculada uma proposta de centralização da seleção de conteúdos e sua uniformização, baseada no argumento de autoridade dos especialistas das disciplinas. [...] O significado dessa Base é a instituição de um conhecimento dito oficial e de um único saber que será considerado o legítimo, ou seja, aquele que consta dos componentes curriculares desse instrumento, além de justificar a existência do sistema de avaliaçóes externas. [...] A BNCC proposta reforça as tendências internacionais de centralizaçáo curricular verificadas nos países centrais do capitalismo com o objetivo de controle político-ideológico do conhecimento, viabilizando a avaliação em larga escala, externa às unidades escolares, e, em consequência, responsabilizando os professores e os gestores pelos resultados da aprendizagem, desconsiderando as condiçóes efetivas da realização das atividades educacionais, como a infraestrutura disponível nas escolas e as condiçóes de trabalho docente. Por essas razóes, o ANDES-SN se posiciona contra a BNCC por considerá-la um instrumento centralizador, autoritário, reducionista e de controle dos conteúdos a serem ministrados por professores/as da Educação Básica [...]. ${ }^{23}$

A CNDE avaliou que o MEC, além de ter se furtado "à responsabilidade de propor um currículo ao Ensino Médio", não teria considerado os implementadores da BNCC, o que

[...] deve gerar forte e justificada oposição da comunidade educacional, que se espalha por todo o país e é muito mais ampla em representatividade e pluralidade do que o grupo que interage e busca legitimar - ainda que de forma constrangida - o MEC, composto por poucas associações de base empresarial, praticamente restritas à ponte área São Paulo-Rio de Janeiro ${ }^{24}$.

Enquanto as organizações de representação político-setorial produziram manifestos, cartas abertas, notas públicas e abaixo-assinados, os agentes cujo capital principal é acadêmico, centralmente pesquisadores de faculdades de educação de universidades públicas, produziram seus "posicionamentos críticos" por meio de documentos científica e academicamente lastreados, como artigos, livros e anais de eventos, vários dos quais podem ser encontrados nas referências do presente artigo. $\mathrm{O}$ tema também foi discutido amplamente em eventos acadêmicos. A Associação Nacional de Pós-Graduação e Pesquisas em Educação (Anped), por exemplo, produziu

[...] um conjunto de posicionamentos críticos acerca da proposição de uma Base Nacional Comum Curricular. São elementos presentes nesta crítica tanto a metodologia de elabora- 
çấo que privilegia especialistas e subalterniza o diálogo com as comunidades escolares quanto suas evidentes implicaçóes nos processos de avaliaçấo, de ensino e aprendizagem, na homogeneização das matrizes curriculares, na formação de professores e autonomia das escolas que se fragilizam com a lógica de centralização que a BNCC instaura na educação escolar ${ }^{25}$.

Sublinhe-se, mais uma vez, que tais estratégias não foram necessariamente excludentes entre si e buscaram, por diferentes vias, contestar o esforço de consensualização em torno da Base. Logo, mesmo quando feita desde fora, a crítica não pode ser entendida como uma esfera à parte, posto que busca justamente inundar o empreendimento de legitimação.

\section{Recorrências discursivas na esfera crítica}

A partir de um repertório de ação e de um corpo bastante amplo de produção simbólica, exemplificado nos excertos acima, foi possível perceber recorrências discursivas na esfera crítica, sistematizadas a seguir.

1 Oposição à ideia de que uma base curricular é necessária:

1a Reivindicação de que as próprias práticas escolares produzem saberes curriculares;

1b Defesa da ideia de que o país já conta com documentos curriculares suficientes.

2 Concordância com a necessidade de uma base comum, mas acompanhada de críticas:

2a Ao conteúdo e à estrutura da BNCC: à centralização e a homogeneização da Base, que dariam primazia a áreas centrais em exames padronizados internacionais de avaliaçáo de desempenho e classificação (rankings); a componentes específicos da norma e seu foco em "competências"; à exclusão do Ensino Médio da norma, pois isso abriria espaço para retirar tal nível da concepção de "educação básica"; ao tratamento dado a questóes de gênero e diversidade, bem como ao espaço galgado pelo ensino religioso, concebido como uma "agenda imposta" por um "lobby empresarial e religioso"26. Ao mesmo tempo, a Frente Parlamentar Evangélica atacou o que chamou de "ideologia de gênero", crítica que a norma acabou por integrar, implicando inclusive na exclusão dos termos "gênero" e "orientação sexual" 27 . Esta foi uma das poucas derrotas do $\mathrm{MpB}$, que chegou a fazer um manifesto contra a referida exclusão ${ }^{28}$.

$2 \mathrm{~b}$ Aos agentes que encabeçaram o processo, $\mathrm{o}$ qual teria privilegiado especialistas, pesquisadores estrangeiros e agentes privados que concentram capital econômico, que careceriam de legitimidade para arbitrar sobre o tema. A propósito, Silva et al. (2015, p.340) demonstram que a proposta do documento feita em 2015, "contou com um número expressivo de professores/as da Educação Básica, bem maior em relação ao documento de 2014", que tinha mais elaboradores vinculados ao Ensino Superior. Os autores argumentam que isso aumentaria a legitimidade da norma junto à comunidade escolar. Porém, outra leitura possível é a de que tal mudança se deve também à oposiçáo que vários pesquisadores vinculados à Educação Superior apresentaram à Base. E, ainda, de que o núcleo propulsor optou por se lastrear em especialistas de instituiçóes acadêmicas internacionais.

2c Ao processo de construção da BNCC: à falta de espaço efetivo para críticas e contribuições e à "instrumentalização da participação" - o que foi alcunhado de "participacionismo", com "objetivo muito mais publicitário do que democrático"29; à temporalidade do processo, ao "atropelo" com que a BNCC teria sido conduzida. Curiosamente, tal aspecto foi criticado também por atores de dentro do núcleo que a encaminhou. Mesmo o Centro Lemann de Stanford não se considera contemplado nas críticas e sugestốes estabelecidas às diferentes versôes da Base, imputando isso ao fato de que "o pessoal das fundaçóes tem pressa, precisa cumprir metas como em empresas"30.

Diante dessa multiplicidade de críticas, o núcleo de agentes que encaminhou a Base buscou 
circunscrever o debate. Embora não estatuído formalmente, operou-se a partir de uma classificação entre posicionamentos tidos por plausíveis e pleitos considerados inadmissíveis, como evidenciado nas palavras do ministro da educação ao homologar a norma: "não ficamos preso (sic) ao debate estéril e que muitas vezes é tomado por ideologias radicais, muito longe disso". Eram consideradas "radicais" as críticas às quais se atribuía teor "ideológico", e que ultrapassavam a substância do documento, ou seja, que incidiam sobre a premissa de que um novo documento era necessário, bem como aquelas sobre os agentes envolvidos e o desenrolar do processo.

Contudo, como os enunciadores detinham capital simbólico, seja científico-acadêmico, seja político-democrático, suas críticas alteraram alguns aspectos do discurso dos agentes propulsores da matriz curricular. Por exemplo, pelo fato de o "common core" em moldes internacionais ter sido alvo de críticas, passou-se a enunciar, ao longo dos debates, que o processo no Brasil teria sido mais "participativo e democrático" do que o ocorrido em outros países, e que, aqui, não se tratava de um "common core". Além disso, em reação às críticas de tipo 1, passou-se a afirmar recorrentemente que "a base não é currículo" ${ }^{\text {"31. }}$.

Como se buscava legitimar o documento de acordo com quesitos técnicos e democráticos, a crítica devia figurar no seu processo de constituição. Não obstante, as posições críticas que não se viram contempladas continuarão a recusar a anuência de legitimidade à Base.

\section{Das relaçóes entre crítica e legitimação}

A própria iniciativa de construção da $\mathrm{BNCC}$ parte de um diagnóstico crítico sobre a educação brasileira e baseia-se na "necessidade de mudanças" no ensino do país. Sobre isso, é relevante retomarmos a análise que Boltanski (2009, p.203) estabelece sobre o que chama de "regime de dominação complexo", o qual se apoiaria no argumento da mudança, apresentada como necessária e inelutável. Baseado em trabalho feito a quatro mãos com Bourdieu, ainda nos anos 1970, o autor afirma que as elites políticas e econômicas em posiçóes de poder se pretendem inovadoras e modernizantes e se consideram "responsáveis" pela mudança (Boltanski, 2009, p.194). Tais agentes, que formulam ou se servem de tais representaçôes da realidade, têm também mais poder de torná-las reais, uma vez que dispóem de meios para direcionar as mudanças (Boltanski, 2009, p.204); isto é, conseguem modificar os contornos do que o autor conceitua como "realidade", preservando-a ao mesmo tempo. Todavia, eles não se responsabilizariam por tais mudanças, na medida em que as concebem ou enunciam como inevitáveis. Esse caráter de necessidade seria primordial para legitimar a ação política, pois uma ação necessária aparece como o contrário de uma ação arbitrária e, portanto, legitima-se mais facilmente, já que seu componente político se esvanece. Ao insistirem na inevitabilidade da mudança, eles aproximam necessidade e vontade e instam a "desejar o necessário". Trata-se de uma composição discursiva entre a suposta neutralidade da mudança prescrita pela realidade e o objetivo do bem comum.

Também quando instituições precisam se justificar, elas procuram reduzir o "mundo" à "realidade", isto é, tentam assegurar que a ordem que procuram implementar ou legitimar confunde-se com o necessário, com aquilo que não poderia ser de outro modo. No entanto, os arranjos que constituem a "realidade" são frágeis, pois a crítica sempre pode buscar no "mundo" contradiçóes na lógica da "realidade", o que pode abrir caminho para novos acordos. (Boltanski, 2009, p.93).

Desse modo, tais regimes de poder estabelecem uma relação complexa com a esfera da crítica. Ao invés de recusá-la ou reprimi-la, buscam absorvê-la e reinterpretá-la nos termos das instâncias institucionais, incorporá-la aos moldes do funcionamento normal da realidade, de sorte que ela só pode ser explicitamente ouvida dobrando-se aos formatos previstos. Como há uma triagem entre modos legítimos de crítica e formas consideradas fora dos quadros legais ou aceitáveis, o espaço da "crítica política” é restrito, já que esta bebe na exterioridade do mundo, para colocar a realidade em questão. Essa maneira de manejar a crítica, incorporando-a, é reforçada pelo fato de que a "dominação pela mudança” incumbe-se também da crítica, mas de uma "crítica interna". Por apoiar-se na "expertise" 
que pretende dizer o que a realidade é, por oposição ao que ela poderia ou deveria ser, às possibilidades existentes no mundo, tal modalidade de gestão da crítica busca escapar ao antagonismo "realismo versus construcionismo", e enquadra as querelas no embate entre expertise e contra-expertise (Boltanski, 2009, p.205-206).

Ao analisar a "circulação internacional de expertise" no que denominam "mercado de saberes de reforma”, Yves Dezalay e Olivier Nay (2015, p.195) também apontam a "incorporação dos saberes críticos" em programas governamentais baseados em "redes colaborativas". Os autores apontam que, longe de se tratar de um movimento democratizante, a constituição de fóruns em que as posiçóes dissidentes podem ser integradas ao debate público - sob a condiçáo de serem formuladas em uma linguagem "compatível" - oferece aos experts do Estado a possibilidade de incorporar pontos de vista críticos e dissidentes, de forma lenta e não conflituosa, e de digeri-los entre seus próprios quadros normativos.

Diante disso, podemos retomar nossa reflexão sobre as relaçóes entre crítica e legitimação no processo em análise. A expectativa inicial das fundaçóes privadas envolvidas na criação da BNCC, assim como a de vários agentes do poder público, era a de que o processo fosse restrito à esfera de "especialistas" 32 . Porém, o núcleo fomentador da BNCC não conseguiu circunscrever o assunto, visto que o discurso puro da técnica não foi capaz de sustentar a empreitada de construção de uma base curricular nacional. Diante disso, os agentes em posições dominantes comporão uma adequação discursiva que, nos termos de Boltanski e Thévenot (1991; 1999), buscará contemplar duas "ordens de grandeza" no esforço de justificação: a "cité civique", que tem por valores a coletividade e a democracia; e a "cité industrielle", cujos valores são a ciência e a eficiência, além de lidar com a "cité de l'opinion", na qual a reputação e o reconhecimento dos atores envolvidos têm papel central.

Porém, esta operação não é evidente, pois o discurso da técnica se inscreve na esfera do necessário, daquilo que não passa por deliberação e "deve" ser feito da "melhor" maneira, de acordo com as concepçôes de "especialistas". Não há lugar nem para o dissenso, nem para o consenso, pois no discurso da técnica não cabe posicionamento. Ele se pretende "pós-político" (Wilson e Swyngedouw, 2014). Já o discurso da "vontade geral" é construído como o avesso da necessidade, erigindo-se como fruto de deliberação política, de construção de consensos mínimos, do embate político. Trata-se, portanto, de uma construção discursiva complexa, porque são discursos que dificilmente se coadunam. A associação entre vontade e necessidade, apontada por Boltanski (2009), não deixa de ser uma composição problemática, que deixa brechas na realidade. No caso em tela, tais brechas abrem espaço para críticas às premissas sobre as quais se buscou legitimar a Base.

Ainda assim, o documento foi constituído. Isso porque as críticas estiveram presentes em seu processo de feitura, mas este não constituiu uma "controvérsia", ao menos no sentido conferido ao termo pela Sociologia da Controvérsia. A despeito de qualquer assimetria existente de fato, em uma "controvérsia" as partes adversárias devem, ao menos formalmente, ser iguais quanto à possibilidade de fazer valer seus argumentos diante do "público", composto estritamente por pares considerados em posição de julgar, e não pelo público em geral (Lemieux, 2007, p.195-6). Se o público se alarga, já não teríamos uma controvérsia, mas uma "crise institucional”, pois a participação efetiva da sociedade poderia abrir o processo ao imponderado. $\mathrm{O}$ "mundo" poderia irromper sobre a "realidade". Entretanto, se em uma "controvérsia" não há espaço para o público em geral, nela a dimensão performativa é instituinte, ou seja, o resultado da querela estaria, em princípio, aberto. Ela se define, pois, por algum componente de "indeterminação".

No processo que analisamos, entretanto, não houve uma disputa "indeterminada" entre especialistas, mas uma divisão entre "expertise" e "contra-expertise”, com posiçôes desiguais. Além disso, ele escapou aos especialistas, mas, ainda assim, não houve abertura propriamente dita - o que os próprios agentes de fora do núcleo formador da Base apontaram de forma recorrente e incisiva. Não queremos dizer, com isso, que as críticas foram vazias de consequências ou "efeitos sociais", uma vez que foram elas que instauraram o debate e algumas de- 
las mudaram seus termos, como vimos no caso do slogan "Base não é currículo". Contudo, a desigualdade das posiçóes dos agentes em disputa fez com que a possibilidade de alcance da crítica variasse. Por exemplo, embora ocupasse uma posição central, o MpB foi sobrepujado pela força assumida atualmente no país por representantes políticos ligados a religióes evangélicas. É a posição relativa das elites políticas que enunciam a crítica à dita "ideologia de gênero" que faz com que tal crítica seja encampada pela BNCC. Críticas oriundas de outras posições foram ou rechaçadas como radicais, ou incorporadas nos termos do processo de concertação discursiva, que enuncia a Base como participativa, plural, democrática... Contudo, a tarefa de tentar justificar uma realidade assim construída é inesgotável ${ }^{33}$.

\section{Conclusáo: Por uma abordagem multidimensional das disputas sociais}

Ainda que possa haver estratégias de consensualização e de crítica que não apareceram na pesquisa que deu origem ao presente artigo, o material exposto permite afirmar que a BNCC chega ao final de seu périplo de criação e homologação com seus agentes propulsores estatuindo-a como realidade técnica e democrática e, por isso, legítima. Ao mesmo tempo, ela chega ao limiar de seu processo de implementação - que se anuncia problemático por várias razóes, inclusive por ela carecer de legitimidade junto a implementadores - com muitos agentes em outras posiçóes no espaço social declarando-a ilegítima. Por um lado, não houve propriamente indeterminação na criação da BNCC, já que as posiçóes dominantes conseguiram levar a cabo o seu propósito e concluir o documento. Contudo, o processo foi mais complexo do que o antecipado e, mesmo depois de homologada, a Base enfrenta oposição e crítica.

A iniciativa de consensualização que analisamos teve a crítica como elemento constituinte, pois partiu de uma "crítica interna" à qualidade da educação no Brasil e procurou legitimar-se por meio da absorção de críticas internalizáveis. Paralelamente, tentou repelir as críticas consideradas inintegráveis, isto é, aquelas que colocavam em questão as premissas, os agentes constitutivos ou o processo de realização da iniciativa, especialmente se manifestadas a partir "de fora" do núcleo institucionalizante. Em suma, tentou refutar críticas que - em sua forma, conteúdo ou origem social - eram consideradas irrealistas ou radicais, por atacarem os fundamentos da empreitada. Contudo, as tentativas de bani-las não lograram neutralizá-las completamente. Inclusive, em etapas subsequentes da criação da Base Curricular Nacional, alguns agentes críticos lançaram mão de táticas para evidenciar os mecanismos de administração e neutralização da crítica empregados pelos agentes dedicados à consensualização ${ }^{34}$. A realidade não é revogada pela crítica, tampouco fica incólume a ela.

Assim, o espaço social que analisamos é constituído por disputas que passam por conversôes de capitais e por relaçôes complexas entre crítica e legitimação que os próprios atores estabelecem entre si. Entretanto, nem a crítica nem a justificaçâo são dotadas de uma capacidade performativa independente das posiçóes relacionais a partir das quais são apresentadas. A depender das posiçôes dos agentes que buscam justificar determinada realidade e daqueles que proferem críticas contra ela, bem como dos conteúdos que trazem e das formas como o fazem, há chances maiores ou menores de eles conseguirem efetivar suas críticas, e de elas serem deglutidas ou excluídas do debate considerado plausível - o que, reitere-se, não faz com que elas deixem de existir.

Diante do exposto, as dimensóes relacionais, discursivas e performativas das disputas devem ser pensadas conjuntamente. No entanto, formas discursivas e práticas performáticas não independem das posiçôes relacionais. Estas são, ao mesmo tempo, um condicionante e um alvo das iniciativas concorrentes, elas mesmas baseadas em apreensões relacionais dos capitais, gramáticas, motivos, meios e modos de ação das posições em disputa. Se isso estava anteposto nos trabalhos bourdieusianos sobre as lutas pela reprodução ou transformação de campos determinados, a compreensão das dinâmicas sociais de legitimação e crítica ganha acuidade por meio de análises que "levem a sério" a reflexividade dos atores e sua "capacidade 
crítica”, as quais, sublinhamos, são exercidas em situação e ancoram-se em posições relacionais frequentemente desiguais.

\section{Notas}

1 A "Frente Parlamentar Evangélica", chamada também de "Bancada Evangélica", tem assumido centralidade nas discussôes sobre educação na Câmara, trazendo propostas como a retirada do termo "gênero" do PNE e da BNCC.

2 Simielli e Alves (2011, p.15), ao analisar as duas "coalizóes em educação no Brasil”, apontam que a CNDE "é formada principalmente por movimentos sociais e organizaçóes não-governamentais", enquanto o "TPE é basicamente formado por indivíduos que representam empresas privadas, seus institutos e fundaçóes".

3 Para as listas completas, consultar https://Undime. org.br/institucional/parceiros http://www.consed. org.br/parceiros, acesso em 12/07/2017.

4 Disponível em http://movimentopelabase.org.br/o-movimento/, acesso em 15/07/2017.

5 Para a lista completa, consultar http://movimentopelabase.org.br/o-movimento/, acesso em 17/07/2017.

6 Lei disponível em http://www.planalto.gov.br/ccivil_03/_ato2011-2014/2013/lei/l12796.htm. Acesso em 03/08/2017. Tramitação disponível em http:// www.camara.gov.br/proposicoesWeb/fichadetramitacao?idProposicao=438125, acesso em 21/08/2017.

7 O chamado "common core", ou núcleo comum, é centrado em conhecimentos priorizados em testes internacionais padronizados que permitem a comparação entre países, tais como leitura e matemática. Para mais detalhes, consultar Macedo (2014; 2016a), bem como a ampla literatura discutida pela autora.

8 A pesquisa privilegiou a atuação da Fundação Lemann em razão da centralidade assumida pela organização no encaminhamento da BNCC. Entre 2015 e 2017, realizamos observação de campo em eventos ocorridos na Columbia University, em Nova York, no Lemann Center da Stanford University e em São Paulo.

9 Para se ter uma ideia da ampla cobertura, consultar http://especiais.g1.globo.com/educacao/2017/tudo-sobre-a-base-nacional-comum-curricular/. Acesso em 12/11/2017. Ver também https://g1.globo.com/ educacao/noticia/leia-a-opiniao-de-especialistas-sobre-a-terceira-versao-da-base-nacional-comum-bncc. ghtml, acesso em 12/06/2017.
10 Conversa com a autora, em outubro de 2017, no Lemann Center da Stanford University.

11 Disponível em http://basenacionalcomum.mec.gov. br/linha-do-tempo, acesso em 01/11/2017.

12 Disponível em http://basenacionalcomum.mec.gov. br/a-construcao-da-base, acesso 02/11/2017.

13 Disponível em http://movimentopelabase.org.br, acesso em 17/07/2017.

14 Disponível em http://cnebncc.mec.gov.br/, acesso em 06/07/2017.

15 Disponível em http://movimentopelabase.org. $\mathrm{br} /$ acontece/manaus-audiencia-bncc/, acesso em 19/07/2017.

16 Disponível em http://portal.mec.gov.br/component/ content/article?id=58541, acesso em 15/12/2017.

17 Vídeo da cerimônia de homologaçáo disponível em https://www.facebook.com/ministeriodaeducacao/ videos/1571220762925732/, acesso em 20/12/2017.

18 Idem à nota anterior.

19 Para detalhes sobre a sessão, consultar https:// www2.camara.leg.br/atividade-legislativa/comissoes/ comissoes-permanentes/ce/noticias/programacao-para-o-ciclo-de-debates-sobre-o-bncc-dos-dias-31-05-e-02-06, acesso em 21/05/2019.

20 https://www2.camara.leg.br/camaranoticias/noticias/ ADMINISTRACAO-PUBLICA/535651-FORUM-NACIONAL-DE-EDUCACAO-CONSIDERA-BASE-NACIONAL-CURRICULAR-COMUM-ILEGITIMA.html, acesso em 21/05/2019.

21 Embora este evento tenha ocorrido semanas após o Impeachment de Dilma Roussef e da troca da cúpula do MEC e contasse com participantes da nova cúpula, isso não foi mencionado por organizadores ou palestrantes.

22 Disponível em http://www.cnte.org.br/index.php/ comunicacao/noticias/18818-debate-sobre-a-bncc-reune-filiadas-da-cnte-em-recife.html, acesso em 30/07/2017.

23 Disponível em: portal.andes.org.br/imprensa/ noticias/imp-ult-2053556448.pdf, acesso em 25/08/2017.

24 Disponível em: https://danielcara.blogosfera.uol. com.br/2017/04/06/o-mec-esta-em-declinio-e-a-base-curricular-e-prova-disso/, acesso em 06/06/2017.

25 Disponível em http://www.anped.org.br/news/nota-da-anped-sobre-entrega-da-terceira-versao-da-base-nacional-comum-curricular-bncc-ao, acesso em 02/05/2017. 
26 Disponível em http://www.epsjv.fiocruz.br/noticias/ entrevista/temos-um-documento-tecnocratico-e-conservador-produzido-sem-transparencia, acesso em $18 / 12 / 2017$.

27 Representantes parlamentares acusaram ainda "um viés de doutrinação para a esquerda", que precisaria "ser retirado" do documento. Disponível em https://www2.camara.leg.br/camaranoticias/noticias/ EDUCACAO-E-CULTURA/509695-TEXTO-DA-BASE-CURRICULAR-AINDA-NAO-E-IDEAL,-DIZEM-DEBATEDORES-NA-CAMARA.html, acesso em 22/05/2019.

28 Disponível em http://movimentopelabase.org.br/ acontece/sobre-base-identidade-de-genero-e-orientacao-sexual/, acesso em 19/07/2017. Consultar ainda https://www2.camara.leg.br/atividade-legislativa/ comissoes/comissoes-permanentes/ce/noticias/retirada-de-expressoes-relativas-a-orientacao-sexual-e-identidade-de-genero-e-de-regras-sobre-educacao-religiosa-da-bncc-em-debate-3, acesso em 21/05/2019.

29 Disponível em https:/www.nexojornal.com.br/ ensaio/2017/Participa \%C3\%A7\%C3\%A3o-e-participacionismo-na-constru\%C3\%A7\%C3\%A3o-da-Base-Nacional-Comum-Curricular, acesso em 04/12/2017.

30 Conversa com a autora, em outubro de 2017, no Lemann Center da Stanford University.

31 Como exemplo desse componente discursivo, consultar https://www2.camara.leg.br/atividade-legislativa/ comissoes/comissoes-permanentes/ce/noticias/base-nacional-comum-curricular-e-diferente-de-curriculo-afirmam-especialistas, acesso em 21/05/2019.

32 De acordo com conversas da autora com integrantes de organizaçôes pró-Base, em 2015 e 2016.

33 Dias após a homologação do documento pelo MEC, o $\mathrm{MpB}$ começou uma campanha para combater o que passa a chamar de "mitos da BNCC". Material da campanha disponível em http://movimentopelabase. org.br/acontece/mitos-e-fatos-da-bnccl, acesso em 18/01/2018.

34 Organizadas pelo CNE em 2018, as audiências públicas sobre a Base Curricular do Ensino Médio nas quais os participantes se recusaram a observar os protocolos previstos para a crítica e manifestação foram declaradas "canceladas" pelos organizadores. A etapa do Centro-Oeste foi esvaziada pelo público. Ressalte-se que também a recente Reforma do Ensino Médio tem sido uma arena de disputas acirradas. Note-se que tais desdobramentos se anunciam como bons objetos para se pensar a monitoração reflexiva da ação coletiva. Para detalhes sobre a repercussão, consultar https://novaescola.org.br/conteudo/12246/ protesto-marca-cancelamento-da-audiencia-da-bncc-do-ensino-medio-em-belem; http://www.anped.org. $\mathrm{br} /$ news/nota-sobre-audiencia-publica-da-bncc-em-belem; http://www.cartaeducacao.com.br/reportagens/apos-protesto-de-professores-audiencia-publica-sobre-a-bncc-e-cancelada-em-sao-paulo/; http:// movimentopelabase.org.br/audiencias/regiao-norte/; https://g1.globo.com/educacao/noticia/apos-protesto-audiencia-publica-sobre-a-base-nacional-curricular-do-ensino-medio-e-cancelada-em-sao-paulo.ght$\mathrm{ml}$, acesso em 22/05/2019.

\section{BIBLIOGRAFIA}

ADRIÁO, Theresa; OLIVEIRA, Romualdo P. de (orgs.). (2001), Gestão, financiamento e direito à educação: análise da LDB e da Constituição Federal, São Paulo, Xamã.

ADRIÁO, Theresa; PERONI, Vera. (2011), "Consequências da atuação do Instituto Ayrton Senna para a gestão da educação pública: observaçóes sobre 10 estudos de caso". Práxis Educativa, 6, 1: 45-53.

ALVES, Nilda. (2014), "Sobre a possibilidade e a necessidade curricular de uma base nacional comum". Revista e-Curriculum, 12, 3: 1464 - 79.

AVELAR, Marina \& Ball, Stephen J. (2019). "Mapping new philanthropy and the heterarchical state: The Mobilization for the National Learning Standards in Brazil". International Journal of Educational Development, 64, C: 65-73.

BARREIROS, Débora. (2017), "Base Nacional Comum Curricular (BNCC): sujeitos, movimentos e ações políticas”, $38^{a}$ Reunião Nacional da Anped.

BARTHE, Yannick et al. (2013), "Sociologie pragmatique: mode d'emploi”. Politix, 103, 3: 175-204.

BATISTA, Antônio Augusto Gomes et al. (2015), "Centralização e padronização dos currículos: posiçóes e tomadas de posição". 37a Reunião Nacional da Anped.

BOLTANSKI, Luc. (2009), De la critique. Précis de sociologie de l'émancipation, Paris, Gallimard. 
BOLTANSKI, Luc. (1973), "L'espace positionnel : multiplicité des positions institutionnelles et habitus de classe". Revue Française de Sociologie, 14, 1:3-26.

BOLTANSKI, Luc \& THÉVENOT, Laurent. (1991), De la justification: les économies de la grandeur, Paris, Gallimard.

BOLTANSKI, Luc \& THÉVENOT, Laurent. (1999), The sociology of critical capacity. European Journal of Social Theory, 2, 3:359-377. BOTTERO, Wendy \& CROSSLEY, Nick. (2011), "Worlds, fields and networks: Becker, Bourdieu and the structures of social relations". Cultural Sociology, 5, 1: 99-119.

BOURDIEU, Pierre. (1996), "Espaço social e espaço simbólico", in P. Bourdieu, Razóes práticas. Sobre a teoria da açấo, Campinas, SP, Papirus.

BOURDIEU, Pierre. (2004), "Espaço social e poder simbólico" in P. Bourdieu, Coisas ditas, São Paulo, Brasiliense.

BOURDIEU, Pierre. (1989), "Espaço social e gênese das 'classes", in P. Bourdieu, O poder simbólico, Lisboa, Difel.

BRASIL. Ministério da Educação. (2017), Base Nacional Comum Curricular. Educação é a base, Brasília, Ministério da Educação.

CARVALHO, Elma Júlia Gonçalves de. (2017), “A crescente influência do empresariado na elaboração e na execuçáo de políticas públicas para a educação básica brasileira", in V. M. V. Peroni; P. V. Lima (orgs.), Anais do $1^{\circ}$ Seminário $\mathrm{Na-}$ cional Redefiniçōes das fronteiras entre o público e o privado: Implicaçóes para a democratização da educação, UFGRS, Porto Alegre/RS, 05 a 08 de dezembro de 2017.

CÓSSIO, Maria de Fátima. (2014), "Base comum nacional: uma discussão para além do currículo". Revista e-Curriculum, Sáo Paulo, 12, 03: 1570-90. Disponível em https://revistas.pucsp. $\mathrm{br} /$ index.php/curriculum/article/view/21669, consultado em 23/11/2017.

COSTA, Messias. (2002), A educação nas Constituiçôes do Brasil: dados e direçóes, Rio de Janeiro, DP\&A.

CURY, Carlos Roberto Jamil. (2008), "Sistema nacional de educação: desafio para uma educação igualitária e federativa”. Educação \& Sociedade,
29, 105: 1187-209. Disponível em www.scielo.br/pdf/es/v29n105/v29n105a12.pdf, consultado em 17/08/2016.

DEZALAY, Yves \& NAY, Olivier. (2015), Le marché des savoir de réforme: circulations de l'expertise de gouvernement et reproduction des hiérarchies internationales, in J. Siméant (org.). Guide de l'enquête globale en sciences sociales, Paris, CNRS Éditions.

FAIRCLOUGH, Norman. (2001), Discurso e mudança social, Brasília, Editora da UnB.

FOUCAULT, Michel. (2007), A arqueologia do saber, Rio de Janeiro, Forense Universitária.

FREITAS, Luiz Carlos de. (2012), "Os reformadores empresariais da educação: da desmoralização do magistério à destruição do sistema público de educação". Educação e Sociedade, 33, 119: 379- 404.

HORTA, José Silvério Baia. (1997), "A concepção de diretrizes e bases na história da educaçáo brasileira", in C. R. J. Cury ; V. L. A. de Brito ; J. S. B. Horta (orgs). Medo à liberdade e compromisso democrático: Lei de Diretrizes e Bases e Plano Nacional de Educaçáo, São Paulo, Editora do Brasil.

KLÜGER, Elisa. (2017), "Espaço social e redes: Contribuiçôes metodológicas à sociologia das elites". Tempo Social, 29, 3: 83-110.

LAHIRE, Bernard. (2002), O homem plural: os determinantes da ação, Petrópolis - RJ, Vozes.

LEMIEUX, Cyril. (2007), "À quoi sert l'analyse des controverses?", Mil neuf cent. Revue d'histoire intellectuelle, 25, $1:$ 191-212.

LIMAVERDE, Patricia. (2015), "Base nacional comum: desconstrução de discursos hegemônicos sobre currículo mínimo". Terceiro Incluido, 5, 1: 78-97.

MACEDO, Elizabeth. (2016a), "Base nacional curricular comum: a falsa oposição entre conhecimento para fazer algo e conhecimento em si”. Educação em Revista, 32, 2: 45-68.

MACEDO, Elizabeth. (2015), "Base nacional comum para currículos: direitos de aprendizagem e desenvolvimento para quem?”. Educação e Sociedade, 36, 133: 891-908.

MACEDO, Elizabeth. (2014), "Base nacional curricular comum: novas formas de sociabilidade 
produzindo sentidos para educação". Revista e-Curriculum: 12, 03: 1530 - 55 .

MACEDO, Elizabeth. (2016b), "Por uma Leitura Topológica das Políticas Curriculares". Education Policy Analysis Archives/Archivos Analiticos de Politicas Educativas: 24, 26: 1-19.

MICHETTI, Miqueli. (2017), O discurso da diversidade no universo corporativo: "institutos" empresariais de cultura e a conversão de capital econômico em poder político. Contemporânea: 7, 1: 119-146.

PERONI, Vera Maria Vidal; CAETANO, Maria Raquel. (2015), "O público e o privado na educação: Projetos em disputa?” Revista Retratos da Escola, 9, 17: 337-52.

PERONI, Vera Maria Vidal; CAETANO, Maria Raquel. (2014), "Relações entre o público e o privado na educação: o Projeto Jovem de Futuro do Instituto Unibanco", in Gestão de Sistemas e de instituições de ensino: políticas e práticas educacionais. Anais do IX Encontro Nacional da ANPAE Sudeste, UNICID, São Paulo, 2014.

REED, Isaac Ariail. (2013), "Power: Relational, Discursive, and Performative Dimensions". Sociological Theory, 31, 3: 193-218.

SANTOS, Márcia Luzia dos, SILVA, Mariléia Maria da. (2017), "Filantropia e o silencioso processo de privatização da educação básica", in $\mathrm{V}$. M. V. Peroni; P. V. Lima (orgs.). Anais do $1^{o}$ Seminário Nacional Redefiniçóes das fronteiras entre o público e o privado: Implicações para a democratização da educação, UFGRS, Porto Alegre/RS, 05 a 08 de dezembro de 2017.

SAPIRO, Gisèle. (2006), "Réseaux, institutions et champ”, in D. de Marneffe \& B. Denis (orgs.). Les Réseaux Littéraires, Bruxelas, Le Cri/Ciel.

SAVIANI, Dermeval. (2007), História das idéias pedagógicas no Brasil, Campinas, Autores Associados.

SERINO, Marco et al. (2017), "Bridging social network analysis and field theory through multidimensional data analysis: the case of the theatrical field". Poetics, 62: 66-80.

SILVA, Ileizi Luciana Fiorelli et al. (2015), "A proposta da Base Nacional Comum Curricular e o debate entre 1988 e 2015". Ciências Sociais Unisinos, 51, 3: 330-42. Disponível em revistas.unisinos.br/index.php/ciencias_sociais/ article/view/csu.2015.51.3.10, consultado em 07/04/2017.

SIMIELLI, Lara Elena Ramos; ALVES, Mário Aquino. (2011), "Empresas Agindo como Atores Políticos: Um Estudo de Caso Sobre uma Coalizão em Educação no Brasil". XXXV Encontro da ANPAD, Rio de Janeiro, 4 a 7 de setembro de 2011.

SOUSA, Jorge Luis Umbelino de. (2015), "Currículo e projetos de formação: Base Nacional Comum Curricular e seus desejos de performance". Espaço do Currículo, 8, 3: 323-34.

URBINI, Lia. (2015), Educação integral e capital financeiro: A participação do Itaú Unibanco nas políticas públicas de educação entre 2002 e 2014. Dissertação de mestrado, UFSC, Florianópolis.

YADA, Leonardo. (2016), A atuaçâo prático-discursiva da Fundação Lemann: o curso "gestão para sala de aula" e o movimento pela base nacional comum. Trabalho de conclusão de curso, CGAP- FGV, São Paulo.

WILSON, Japhy \& SWYNGEDOUW. Erik. (Eds.). (2014), The Post-Political and its Discontents: Spaces of Depoliticization, Spectres of Radical Politics, Edinburgh, Edinburgh University Press. 


\section{ENTRE A LEGITIMAÇÃO E A CRÍTICA: AS DISPUTAS ACERCA DA BASE NACIONAL COMUM CURRICULAR}

\section{Miqueli Michetti}

Palavras-chave: Base Nacional Comum Curricular; Fundações empresariais e familiares; Estratégias de legitimação; Pierre Bourdieu; Sociologia da crítica.

$\mathrm{O}$ artigo analisa as recentes disputas sobre a criação da chamada Base Nacional Comum Curricular (BNCC). Diferentemente de outras abordagens sobre o objeto, o texto busca integrar as dimensôes relacional e discursiva para analisá-lo, valendo-se de uma apropriação particular das contribuiçóes de Pierre Bourdieu e da Sociologia da Crítica. A partir de levantamento documental, entrevistas e observaçôes de campo em audiências públicas e em eventos promovidos por fundaçóes familiares e empresariais no Brasil e nos EUA, o artigo apresenta o espaço social da disputa em torno da Base e discute oito estratégias de consensualização estabelecidas pelos agentes que a encaminharam, com foco na concertaçáo discursiva composta por eles e na atuação prático-discursiva das referidas fundaçóes. $\mathrm{Na}$ sequência, são examinadas também as críticas proferidas por agentes contrários ao documento, bem como as relaçôes entre crítica e legitimação no processo de criação da BNCC. À luz dos achados empíricos, a conclusáo do texto aponta para a conveniência de uma abordagem multidimensional das disputas sociais.

\section{ON LEGITIMATION AND \\ CRITIQUE: THE DISPUTES ABOUT THE BRAZILIAN LEARNING STANDARDS}

\section{Miqueli Michetti}

Keywords: Brazilian Learning Standards, Family and Corporate Foundations, Legitimation Strategies, Pierre Bourdieu, Sociology of Critique.

This paper analyzes the recent disputes about the so-called Brazilian Learning Standards. Unlike other approaches to the subject, the text seeks to integrate the relational and discursive dimensions to analyze them and employs a particular appropriation of both Pierre Bourdieu and the Sociology of Critique. The paper is based on document analysis, interviews and field observations in public hearings and events promoted by family and corporate foundations in Brazil and the USA. After presenting the social space of the dispute around the National Learning Standards, the article discusses eight strategies of consensualization established by the agents who advanced it, focusing on the discursive concertation which they composed and on the practical-discursive agency of those foundations. Next, the paper examines the criticisms made by agents against the document and analyzes the relations between critique and legitimation in the process of creating the national curriculum standard. In light of the empirical findings, the conclusion of the text points out the convenience of a multidimensional approach to social disputes.

\section{ENTRE LÉGITIMATION ET CRITIQUE: LES LITIGES À PROPOS DE LA BASE NATIONALE COMMUNE CURRICULAIRE}

\author{
Miqueli Michetti
}

Mots-clés: Base Nationale Commune Curriculaire; Fondations entrepreneuriales et familiales; Stratégies de légitimation; Pierre Bourdieu; Sociologie de la critique.

L'article analyse les disputes récentes concernant la création de ce qui a été appelé de Base Nationale Commune Curriculaire (BNCC). Contrairement à d'autres approches sur l'objet, le texte tente d'intégrer les dimensions relationnelles et discursives pour analyser cet objet, en employant une appropriation particulière des contributions de Pierre Bourdieu et de la Sociologie de la Critique. À partir d'une étude documentaire, des interviews et des observations sur le terrain lors d'audiences publiques et d'événements promus par des fondations familiales et commerciales au Brésil et aux États-Unis, l'article présente l'espace social du litige autour de la Base et discute huit stratégies de consensus établies par les agents qui les ont transmises, en se concentrant sur la concertation discursive qu'ils ont composée et sur l'action pratique-discursive de ces fondations. Par la suite, les critiques formulées par des agents contraires au document, ainsi que les relations entre la critique et la légitimation dans le processus de création de la BNCC, sont également examinées. À la lumière des résultats empiriques, la conclusion du texte souligne la commodité d'une approche multidimensionnelle des conflits sociaux. 